Article

\title{
Isolation, Molecular Identification, and Mycotoxin Production of Aspergillus Species Isolated from the Rhizosphere of Sugarcane in the South of Iran
}

\author{
Maryam Tavakol Noorabadi ${ }^{1}$, Valiollah Babaeizad ${ }^{1}$, Rasoul Zare ${ }^{2}$, Bita Asgari ${ }^{2}$, \\ Miriam Haidukowski ${ }^{3}$ (D), Filomena Epifani ${ }^{3}$, Gaetano Stea ${ }^{3}$, Antonio Moretti ${ }^{3}$ **(D), \\ Antonio Francesco Logrieco ${ }^{3}$ and Antonia Susca ${ }^{3, *(\mathbb{D})}$ \\ 1 Department of Plant Protection, Sari Agricultural Sciences and Natural Resources University, \\ 4818168984 Sari, Iran; maryam.tavakol65@yahoo.com (M.T.N.); babaeizad@yahoo.com (V.B.) \\ 2 Iranian Research Institute of Plant Protection, Agricultural Research, Education and Extension \\ Organization (AREEO), 198513111 Tehran, Iran; simplicillium@gmail.com (R.Z.); \\ bita_asgari@yahoo.com (B.A.) \\ 3 Institute of Sciences of Food Production, National Research Council of Italy, 70126 Bari, Italy; \\ miriam.haidukowski@ispa.cnr.it (M.H.); filomena.epifani@ispa.cnr.it (F.E.); gaetano.stea@ispa.cnr.it (G.T.); \\ antonio.logrieco@ispa.cnr.it (A.F.L.) \\ * Correspondence: antonio.moretti@ispa.cnr.it (A.M.); antonella.susca@ispa.cnr.it (A.S.); \\ Tel.: +39-080-592-9326 (A.M.); +39-080-592-9330 (A.S.)
}

Received: 13 January 2020; Accepted: 12 February 2020; Published: 14 February 2020 updates

\begin{abstract}
Knowledge of the genetic diversity detected among fungal species belonging to the genus Aspergillus is of key importance for explaining their important ecological role in the environment and agriculture. The current study aimed to identify Aspergillus species occurring in the rhizosphere of sugarcane in the South of Iran, and to investigate their mycotoxin profiles. One-hundred and twenty-five Aspergillus strains were isolated from the soil of eight major sugarcane-producing sites, and were molecularly identified using sequences of partial $\beta$-tubulin (ben $A)$ and partial calmodulin (CaM) genes. Our molecular and phylogenetic results showed that around $70 \%$ of strains belonged to the Aspergillus section Nigri, and around 25\% of species belonged to the Aspergillus section Terrei. Species belonging to both sections are able to produce different mycotoxins. The production of mycotoxins was measured for each species, according to their known mycotoxin profile: patulin (PAT) and sterigmatocystin (STG) for Aspergillus terreus; ochratoxin A (OTA) and fumonisins for Aspergillus welwitschiae; and OTA alone for Aspergillus tubingensis. The data showed that the production of OTA was detected in only 4 out of 10 strains of $A$. welwitschiae, while none of the $A$. tubingensis strains analyzed produced the mycotoxin. Fumonisins were produced by 8 out of 10 strains of A. welwitschiae. Finally, none of the 23 strains of $A$. terreus produced STG, while 13 of them produced PAT. The occurrence of such mycotoxigenic plant pathogens among the fungal community occurring in soil of sugarcane fields may represent a significant source of inoculum for the possible colonization of sugarcane plants, since the early stages of plant growth, due to the mycotoxin production capability, could have worrisome implications in terms of both the safety and loss of products at harvest.
\end{abstract}

Keywords: Beta-tubulin; calmodulin; fumonisins; ochratoxin A; patulin; mycotoxin; sugarcane; Aspergillus

Key Contribution: Wide sampling of the rhizosphere in sugarcane fields was carried out for eight major sugarcane-producing sites of South of Iran. The prevalence of A. tubingensis, A. terreus, and A. welwitschiae was observed. In all regions sampled, a significant co-occurrence of $A$. tubingensis, A. welwitschiae, and $A$. terreus was detected, highlighting the possible risk of multi-toxin contamination 
(ochratoxin, fumonisins, and patulin) of sugarcane plants in the next cultivation year, due to a significant source of the inoculum of mycotoxigenic species in soil.

\section{Introduction}

Sugarcane (Saccharum officinarum L., family Poaceae) is one of the most important agricultural crop plants in Iran, where it is cultivated in the southern regions, with about 68,350 hectares and an annual production of about 5,685,000 tons [1]. The high importance of sugarcane cultivation is due to its multiple exploitations: production of ethanol coupled with the search for cleaner energy sources, as well as the electrical and/or thermal energy [2] production of citric acid, as the source of key players of fermentation, Aspergillus niger and sugarcane bagasse [3]; production of antibiotics [4], organic acids [5,6] medicines, or enzymes [4,7-9]; and supply of important green material for industries that produce sugar and by-products $[10,11]$. The latter two uses are related to human and animal food consumption, so much attention must be devoted to the safety of sugarcane products, such as possible mycotoxin contamination.

Microbial communities occurring in the soil of sugarcane crops are of biological importance to sugarcane because the crop is produced by successive stalk harvesting from initial stalk-cutting plantations, which are annually left in the soil to produce the next plant generation. Therefore, these stalks represent the major source of inoculum of plant contamination [12]. Indeed, over $90 \%$ of all microorganisms present in roots, stalks, and leaves are also present in bulk soil samples [13], suggesting that the microbial diversity present in the bulk soil is also represented in the plant organs at early stages of plant development. Mycobiota, both in the field and post-harvest, under specific temperatures and humidity, can use the sugar as a source of energy for their growth. Furthermore, they can produce secondary metabolites, such as mycotoxins, which can both cause processing problems in the mill and refinery, and be toxic to animals and humans, e.g., through mycotoxin production [11]. Aspergillus species are among the most important mycotoxigenic fungi. In the genus, there are both species useful for industrial production and species that have harmful effects [14], with strong and varied biological activities ranging from moderate allergies to severe asthma and cancer [15].

The black aspergilli are an important group of fungi that can colonize food, feed at various stages, and cause the bio-deterioration of other materials. One of the species in the section Nigri that is extensively used in biotechnological processes is $A$. niger, whose fermentation process is "generally recognized as safe" by the Food and Drug Administration (FDA) in certain industrial conditions $[16,17]$. However, some species of the section Nigri have been reported as producers of mycotoxins, such as ochratoxin (OTA) and fumonisin (FB2) [18], which can thus affect the safety of sugarcane and its related biotechnological products. The section Terrei includes economically important species, isolated from different sources, that are very important in the fermentation industry $[19,20]$, such as Aspergillus terreus, used to produce different enzymes and organic acids [21]. This species can produce a wide range of metabolites, some of which, like patulin, have important health effects and have been shown to be carcinogenic [22,23].

Because of the increased production of sugarcane in Iran and the level of by-products generated during processing, there is a need to monitor the presence of toxigenic fungal species occurring in soil that have the potential to colonize plants. In this context, we focused on Aspergillus species associated with sugarcane in the South of Iran, and investigated the related biodiversity, through DNA sequencing and possible mycotoxin production in vitro, in order to establish appropriate practices for crop management aimed at reducing the risk of contamination of sugarcane plants. 


\section{Results}

\subsection{Species Identification}

To identify Aspergillus species occurring in the sugarcane rhizosphere in the South of Iran, and to investigate their mycotoxin profiles, 64 samples were collected from eight major sugarcane-producing sites (Table 1). In total, 125 strains of Aspergillus were isolated and, based on morphological characteristics, were primarily divided into five sections, including Circumdati, Flavipedes, Nigri, Terrei, and Usti. However, the majority of strains were included in sections Nigri and Terrei. For precise species identification, all isolates were subjected to a DNA-based analysis of partial $\beta$-tubulin (benA) and partial calmodulin ( $\mathrm{CaM}$ ) genes. The concatenated sequences of benA and CaM, generated in this study, were aligned against the sequences of 13 reference Aspergillus species available at GenBank. Based on our phylogenetic analysis (Figure 1), nine species could be identified: Aspergillus calidoustus (1 strain), Aspergillus japonicus (1), Aspergillus luchuensis (1), A. niger (2), Aspergillus ochraceus (1), Aspergillus templicola (5), A. terreus (29), Aspergillus tubingensis (60), and Aspergillus welwitschiae (25).

Table 1. Occurrence of Aspergillus species isolated from the sugarcane rhizosphere in the South of Iran *.

\begin{tabular}{|c|c|c|c|c|c|c|}
\hline \multirow[b]{2}{*}{ Sampling Sites } & \multirow{2}{*}{$\begin{array}{c}\text { No. of Sugarcane } \\
\text { Rhizosphere } \\
\text { Samples }\end{array}$} & \multirow{2}{*}{$\begin{array}{l}\text { No. of } \\
\text { Aspergillus } \\
\text { Isolates }\end{array}$} & \multicolumn{3}{|c|}{ Aspergillus spp. Occurrence (\%) } & \multirow[b]{2}{*}{ Others } \\
\hline & & & $\begin{array}{c}A . \\
\text { terreus }\end{array}$ & $\begin{array}{c}A . \\
\text { tubingensis }\end{array}$ & $\begin{array}{c}A . \\
\text { welwitschiae }\end{array}$ & \\
\hline Amir Kabir & 8 & 8 & -- & 75 & 12.5 & 12.5 \\
\hline Imam Khomeini & 8 & 4 & 25 & 50 & 25 & -- \\
\hline Debal Khazaei & 8 & 11 & - & 73 & 18 & 9 \\
\hline Dehkhoda & 8 & 10 & 80 & 10 & -- & 10 \\
\hline Karun & 8 & 23 & 25 & 29 & 42 & 4 \\
\hline Mirza K. Khan & 8 & 11 & 9 & 82 & 9 & -- \\
\hline Salman Farsi & 8 & 26 & 19 & 81 & -- & -- \\
\hline Haft Tappeh & 8 & 32 & 21 & 24 & 30 & 24 \\
\hline Total & 64 & 125 & 23 & 48 & 20 & 9 \\
\hline
\end{tabular}

Among the 125 Aspergillus strains, A. tubingensis occurred at a rate of $48 \%$, A. welwitschiae at $20 \%$, and $A$. terreus at $23 \%$, together representing $89 \%$ of the Aspergillus population (Figure 2 ). In most of the Iranian regions, the percentage of Aspergillus section Nigri strains was higher than that of Aspergillus section Terrei. The highest occurrence of A. tubingensis was observed in Amir Kabir, Imam Khomeini, Debal Khazaei, Mirza K. Khan, and Salman Farsi, with a 75\%, 50\%, 73\%, 82\%, and 81\% occurrence, respectively. In only one case (from Dehkhoda), A. terreus displayed the highest occurrence (80\%). On the other hand, $A$. welwitschiae was the most frequent species in Karun and Haft Tappeh regions (42\% and $30 \%$, respectively). 


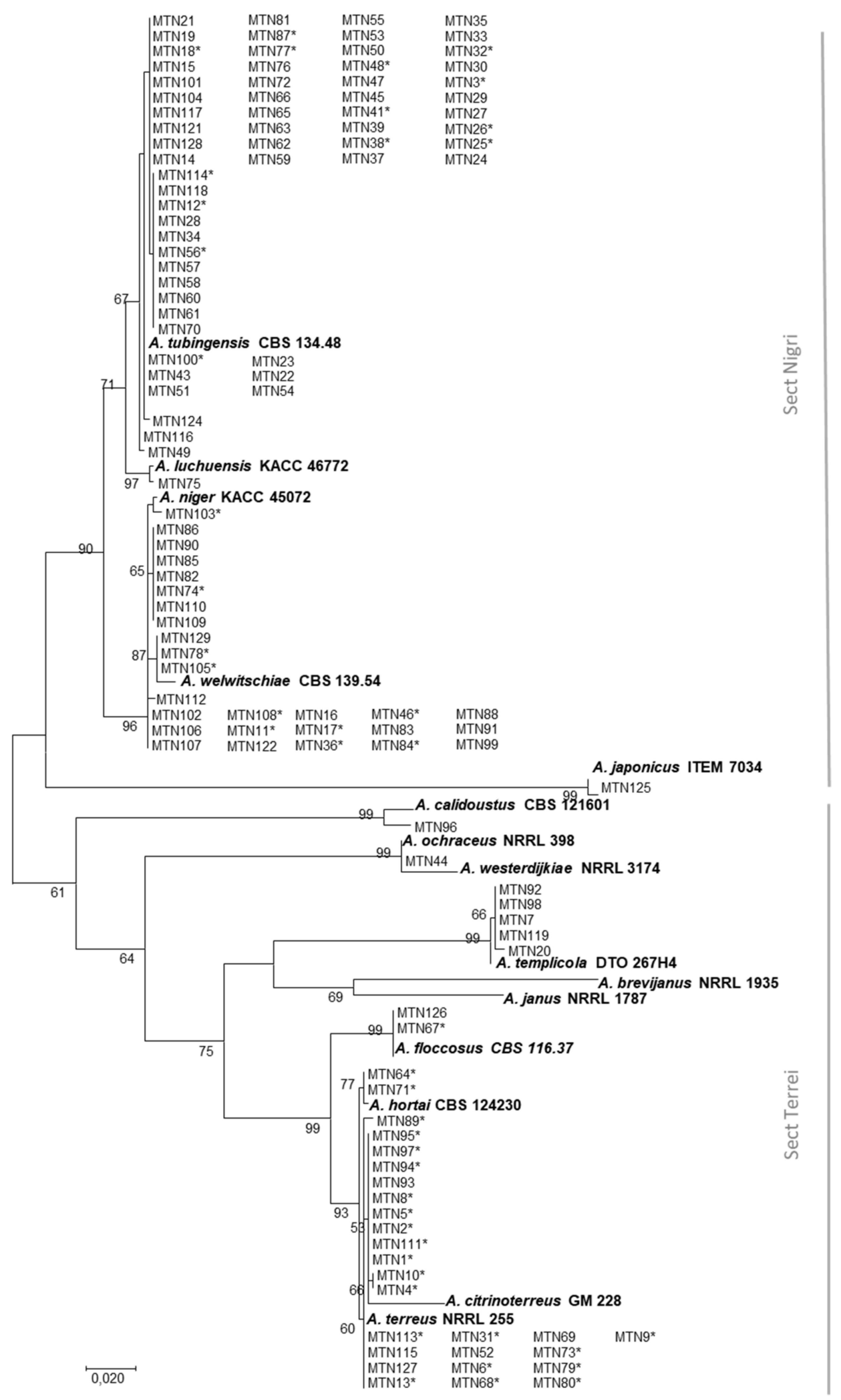

Figure 1. Phylogram generated for 125 strains with maximum likelihood analysis, based on a combined sequence dataset of $\beta$-tubulin and calmodulin (1556 bp). Bootstrap values $>50 \%$ (1000 replicates) are shown above or below the nodes. The scale bar indicates nucleotide substitution in ML analysis. The asterisk $\left.{ }^{*}\right)$ indicates strains tested for mycotoxin production. 


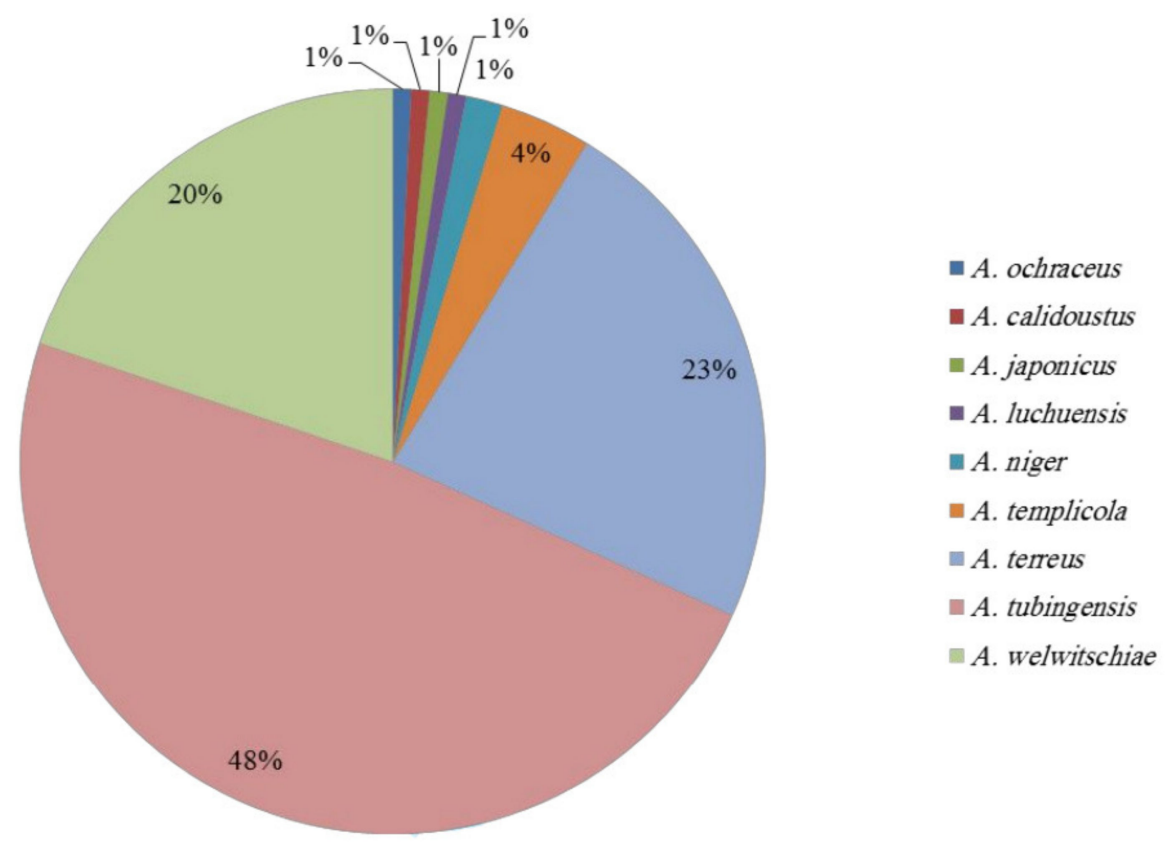

Figure 2. Distribution of Aspergillus species isolated from the sugarcane rhizosphere in the South of Iran.

\subsection{Mycotoxin Production}

Mycotoxin production of a subset of strains, representative of the different sites of isolation, was tested for potential toxigenic species: A. welwitschiae (10 strains), A. tubingensis (15 strains), and A. terreus (23 strains) (see Table 2).

No production of ochratoxin A (OTA) was observed among the 10 tested strains of $A$. welwitschiae, when grown on CY20S; however, on YES medium, four out of the 10 strains produced OTA, in the range of 32 and $142 \mu \mathrm{g} / \mathrm{g}$. None of the 15 A. tubingensis strains, grown on both CY20S and YES media, were able to produce OTA. Fumonisin B2 (FB2) was produced by eight out of $10 \mathrm{~A}$. welwitschiae strains tested (MTN108, MTN46, MTN11, MTN17, MTN105, MTN78, MTN103, and MTN36) in the range of 0.1 and $4.4 \mu \mathrm{g} / \mathrm{g}$, when grown on CY20S. Furthermore, 13 out of the 23 tested strains of A. terreus, on YES, were able to produce patulin (PAT) in the range 0.2 and $523.56 \mu \mathrm{g} / \mathrm{g}$. On the other hand, no production of PAT was recorded by the same strains when grown on CYA. Finally, sterigmatocystin (STG) was not produced by any strain of A. terreus, on both YES and CY20S (Table 2). 
Table 2. Fumonisin (FB2), ochratoxin A (OTA), patulin (PAT), and sterigmatocystin (STG) production by representative strains of toxigenic species: A. welwitschiae, A. tubingensis, and $A$. terreus.

\begin{tabular}{|c|c|c|c|c|c|c|}
\hline \multirow[t]{2}{*}{$\begin{array}{l}\text { ITEM Collection Acc. } \\
\text { Number }\end{array}$} & \multirow[t]{2}{*}{$\begin{array}{l}\text { IRAN Collection } \\
\text { Acc. Number }\end{array}$} & \multirow[t]{2}{*}{ Isolate ID } & \multirow[t]{2}{*}{ Species } & \multicolumn{3}{|c|}{ Mycotoxin Production $(\mu \mathrm{g} / \mathrm{g})$} \\
\hline & & & & FB2 & OTA & PAT * \\
\hline 18460 & 3629 & MTN11 & A. welwitschiae & 1.0 & 106 & n.t. \\
\hline 18461 & 3533 & MTN17 & A. welwitschiae & 1.0 & 32 & n.t. \\
\hline 18462 & 3550 & MTN36 & A. welwitschiae & $<\mathrm{LOD}$ & $<\mathrm{LOD}$ & n.t. \\
\hline 18464 & 3632 & MTN46 & A. welwitschiae & 1.0 & $<\mathrm{LOD}$ & n.t. \\
\hline 18465 & 3583 & MTN74 & A. welwitschiae & $<\mathrm{LOD}$ & $<\mathrm{LOD}$ & n.t. \\
\hline 18466 & 3587 & MTN78 & A. welwitschiae & 0.1 & $<\mathrm{LOD}$ & n.t. \\
\hline 18467 & 3606 & MTN100 & A. tubingensis & n.t. & $<\mathrm{LOD}$ & n.t. \\
\hline 18468 & 3608 & MTN103 & A. welwitschiae & 4.4 & $<\mathrm{LOD}$ & n.t. \\
\hline 18469 & 3609 & MTN105 & A. welwitschiae & 0.2 & 49 & n.t. \\
\hline 18470 & 3612 & MTN108 & A. welwitschiae & 2.2 & 142 & n.t. \\
\hline 18471 & 3521 & MTN3 & A. tubingensis & n.t. & $<\mathrm{LOD}$ & n.t. \\
\hline 18472 & 3528 & MTN12 & A. tubingensis & n.t. & $<\mathrm{LOD}$ & n.t. \\
\hline 18473 & 3530 & MTN14 & A. tubingensis & n.t. & $<\mathrm{LOD}$ & n.t. \\
\hline 18474 & 3534 & MTN18 & A. tubingensis & n.t. & $<\mathrm{LOD}$ & n.t. \\
\hline 18475 & 3541 & MTN25 & A. tubingensis & n.t. & $<\mathrm{LOD}$ & n.t. \\
\hline 18476 & 3542 & MTN26 & A. tubingensis & n.t. & $<\mathrm{LOD}$ & n.t. \\
\hline 18477 & 3547 & MTN32 & A. tubingensis & n.t. & $<\mathrm{LOD}$ & n.t. \\
\hline 18478 & 3552 & MTN38 & A. tubingensis & n.t. & $<\mathrm{LOD}$ & n.t. \\
\hline 18479 & 3554 & MTN41 & A. tubingensis & n.t. & $<\mathrm{LOD}$ & n.t. \\
\hline 18480 & 3559 & MTN48 & A. tubingensis & n.t. & $<\mathrm{LOD}$ & n.t. \\
\hline 18481 & 3567 & MTN56 & A. tubingensis & n.t. & $<\mathrm{LOD}$ & n.t. \\
\hline 18482 & 3586 & MTN77 & A. tubingensis & n.t. & $<\mathrm{LOD}$ & n.t. \\
\hline 18483 & 3595 & MTN87 & A. tubingensis & $<\mathrm{LOD}$ & $<\mathrm{LOD}$ & $<\mathrm{LOD}$ \\
\hline 18484 & 3616 & MTN114 & A. tubingensis & $<$ LOD & $<\mathrm{LOD}$ & $<\mathrm{LOD}$ \\
\hline 18485 & 3520 & MTN1 & A. terreus & n.t. & n.t. & 523.56 \\
\hline 18486 & 3627 & MTN2 & A. terreus & n.t. & n.t. & 18.39 \\
\hline 18487 & 3628 & MTN4 & A. terreus & n.t. & n.t. & n.t. \\
\hline 18488 & 3522 & MTN5 & A. terreus & n.t. & n.t. & n.t. \\
\hline 18489 & 3523 & MTN6 & A. terreus & n.t. & n.t. & 172.39 \\
\hline 18490 & 3525 & MTN8 & A. terreus & n.t. & n.t. & 212.65 \\
\hline
\end{tabular}


Table 2. Cont.

\begin{tabular}{|c|c|c|c|c|c|c|}
\hline \multirow{2}{*}{$\begin{array}{l}\text { ITEM Collection Acc. } \\
\text { Number }\end{array}$} & \multirow{2}{*}{$\begin{array}{l}\text { IRAN Collection } \\
\text { Acc. Number }\end{array}$} & \multirow[t]{2}{*}{ Isolate ID } & \multirow[t]{2}{*}{ Species } & \multicolumn{3}{|c|}{ Mycotoxin Production $(\mu \mathrm{g} / \mathrm{g})$} \\
\hline & & & & FB2 & OTA & PAT * \\
\hline 18491 & 3526 & MTN9 & A. terreus & n.t. & n.t. & n.t. \\
\hline 18492 & 3527 & MTN10 & A. terreus & n.t.. & n.t. & n.t. \\
\hline 18493 & 3529 & MTN13 & A. terreus & n.t. & n.t. & n.t. \\
\hline 18494 & 3546 & MTN31 & A. terreus & n.t. & n.t. & 124.57 \\
\hline 18495 & 3574 & MTN64 & A. terreus & n.t. & n.t. & 7.88 \\
\hline 18496 & 3577 & MTN67 & A. terreus & n.t. & n.t. & n.t. \\
\hline 18497 & 3578 & MTN68 & A. terreus & n.t. & n.t. & 62.05 \\
\hline 18498 & 3634 & MTN71 & A. terreus & n.t. & n.t. & 7.16 \\
\hline 18499 & 3582 & MTN73 & A. terreus & n.t. & n.t. & n.t. \\
\hline 18500 & 3588 & MTN79 & A. terreus & n.t. & n.t. & 154.65 \\
\hline 18501 & 3589 & MTN80 & A. terreus & n.t. & n.t. & 10.70 \\
\hline 18502 & 3636 & MTN89 & A. terreus & n.t. & n.t. & n.t. \\
\hline 18503 & 3601 & MTN94 & A. terreus & n.t. & n.t. & 0.20 \\
\hline 18504 & 3602 & MTN95 & A. terreus & n.t. & n.t. & 510.56 \\
\hline 18505 & 3603 & MTN97 & A. terreus & n.t. & n.t. & n.t. \\
\hline 18506 & 3639 & MTN111 & A. terreus & n.t. & n.t. & n.t. \\
\hline 18507 & 3615 & MTN113 & A. terreus & n.t. & n.t. & 59.46 \\
\hline
\end{tabular}

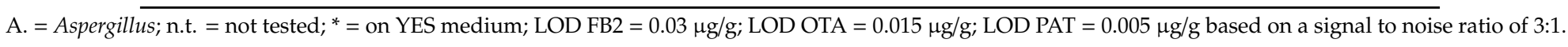




\section{Discussion}

Agricultural crops grow in soils, which usually host enormous types and numbers of micro-organisms, that, from one side, are responsible for soil health by nutrient cycling, while from the other side, can opportunistically infect the plants [24-26]. Among micro-organisms, fungal species of the genus Aspergillus are soilborne micro-organisms, and their predominance in rhizospheric and non-rhizospheric soils has been extensively studied [27]. In this study, we focused our analyses on the isolation and identification of Aspergillus species, since they are well-known mycotoxin-producers and their occurrence in sugarcane soils can be the cause of a subsequent contamination of sugarcane plants that grow in such contaminated soils [28].

The occurrence of Aspergillus species was evaluated in the rhizosphere of eight sugarcane sites in the South of Iran (see Figure 3 and Table 3), where the sugarcane is the main agro-food product. The number of Aspergillus strains isolated in this study varied from region to region: Imam Khomeini and Haft Tappeh sites showed the highest and lowest number of isolates, respectively. These differences in the distribution of strains among the regions might be related to significant specific environmental and biological features of each site, such as the microbiome profile [29,30], fungal antagonist occurrence [31], and soil moisture and temperature [32]. However, inadequate knowledge on the sites sampled prevents us from drawing further conclusions.

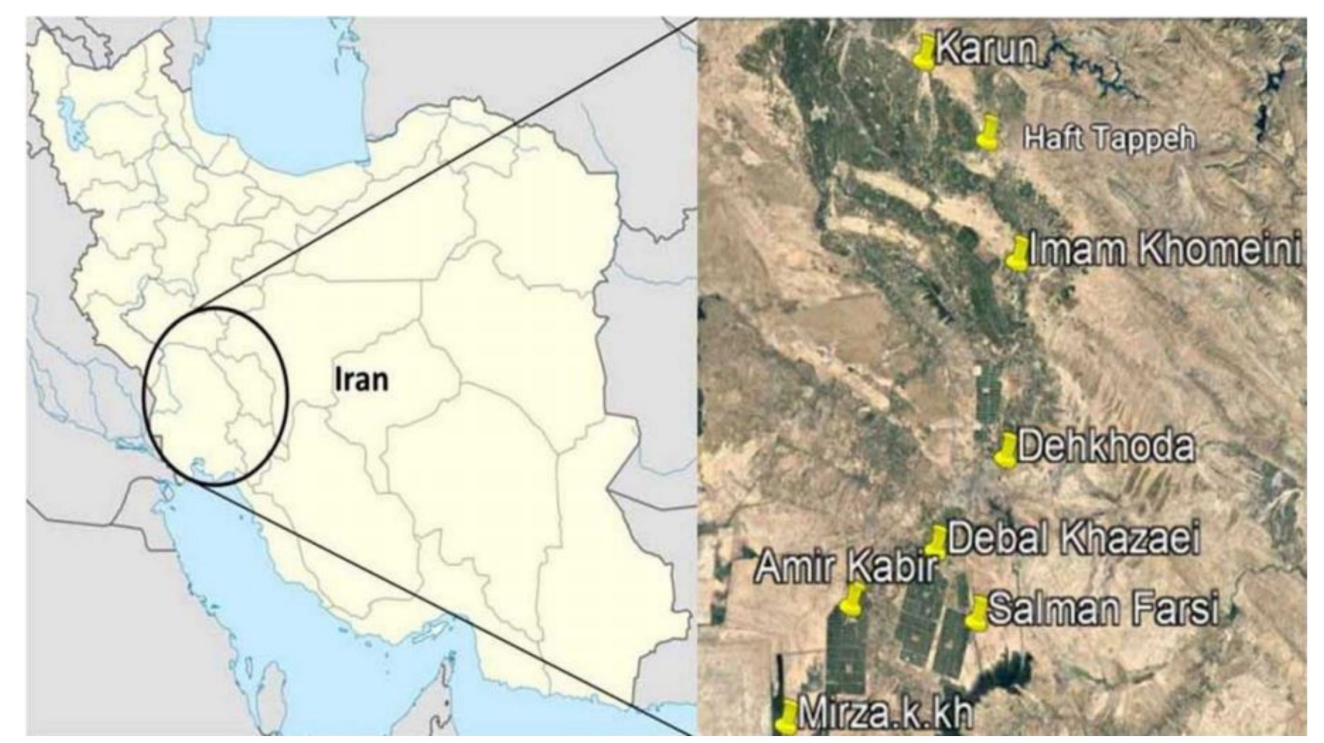

Figure 3. The geographical origins of Aspergillus strains isolated from the sugarcane rhizosphere in the South of Iran. Pins indicate the areas where the rhizosphere samples were collected.

Table 3. GPS coordinates of the geographical origins of rhizosphere samples.

\begin{tabular}{ccc}
\hline Location Name & Latitude & Longitude \\
\hline Karun & 32.290077 & 48.601034 \\
Haft Tappeh & 32.104158 & 48.769371 \\
Imam Khomeini & 31.816312 & 48.835920 \\
Dehkhoda & 31.363858 & 48.754828 \\
Debal Khazaei & 31.151123 & 48.511743 \\
Amir Kabir & 31.030506 & 48.278718 \\
Salman Farsi & 30.974513 & 48.657927 \\
Mirza. K. Khan & 30.739912 & 48.066038 \\
\hline
\end{tabular}

The presence of toxigenic Aspergillus species in the soil associated with sugarcane indicates that a contamination of sugarcane plants in the field and its by-products post-harvest can occur. The heat treatment with which sugarcane juice is processed to obtain molasses and non-refined sugar, leads 
to the removal of fungal contaminants at this stage. However, since we proved a high presence of toxigenic Aspergillus species in the rhizosphere of sugarcane plants, the contamination of the early stages of plant development could be high. Therefore, in the field, environmental conditions suitable for mycotoxin production in planta by the Aspergillus species can easily occur and also lead to the contamination of final products. As a consequence, this contamination can cause a high toxigenic risk for consumers, but can also interfere with sugarcane industrial processing.

Our molecular and phylogenetic results showed that around $70 \%$ of strains belong to the Aspergillus section Nigri, and around 25\% of species belong to the Aspergillus section Terrei. Although no morphological differences were observed among strains assigned to $A$. terreus, a phylogenetic tree divided them into two clades. Interestingly, MTN64 and MTN71, which were morphologically identified as A. terreus, were closely related to A. hortai (CBS124230). A correct identification of Aspergillus species is a key aspect, since many species produce mycotoxins and each species has its own mycotoxin profile. Therefore, a precise risk assessment is strongly linked to the use of advanced diagnostic tools.

As reported above, the species identified in this survey belonged to two main Aspergillus sections-Terrei and Nigri-characterized by distinct mycotoxin profiles: PAT and STG for section Terrei and OTA and FB2 for section Nigri. The in vitro mycotoxin production by different species tested was analyzed according to their known mycotoxin profile: PAT and STG for $A$. terreus and OTA and FB2 for $A$. welwitschiae. However, the production of OTA was also tested for $A$. tubingensis because its ability to produce mycotoxin has been inconsistently reported. Susca et al. [33] demonstrated the lack of some genes in the OTA cluster, most likely related to their inability to produce OTA, while Medina et al. [34] reported OTA production for few strains of A. tubingensis. However, our data confirmed the inability of $A$. tubingensis to produce OTA, since none of the strains tested could produce any trace of the mycotoxin. The fact that this species is the most frequently detected in our study is comforting since it reduces the risk related to the occurrence of mycotoxigenic Aspergillus species.

On the contrary, the presence of $A$. welwitschiae strains that produce both OTA and FB2 is worrisome, since both of these mycotoxins are considered by the International Agency for Cancer Research (IARC) group 2b, meaning potentially carcinogenic. Only a minority of strains analyzed were able to produce only OTA, while the majority of $A$. welwitschiae strains (80\%) also produced FB2, in agreement with previous reports $[33,35]$. Some authors have demonstrated that OTA production in A. niger is affected by temperature [36], while in $A$. welwitschiae, it is affected by water activity and the medium [37]. Our data confirm the high influence of media in the in vitro production of OTA by A. welwitschiae. No strain produced the mycotoxin on CY20S, while $40 \%$ of strains produced it if grown on YES. In addition, since the temperature was proved to affect OTA production, environmental and geographical variations clearly influence the potential of OTA production by A. welwitschiae in the field of a given area.

To the best of our knowledge, in Iran, there is currently a lack of information on the mycotoxin contamination of sugarcane and related by-products. Here, we reported the potential contamination by FB2, OTA, and PAT of sugarcane plants. Additionally, our data suggest the need for further investigations for developing a better understanding of fungal contamination and related mycotoxins in planta, in order for proper management protocols to be adopted and to minimize the risk of contamination of this prestigious food. Finally, the high variability of the Aspergillus species profile in the soils of different regions, the high influence of temperature on their ability to colonize soils, and the rapidity with which the population structure of the genus Aspergillus can change in the soil, together suggest that, by the time a study like this one is published, the data presented in it are historical rather than a profile of an existing Aspergillus population. However, genetic diversity and flux in populations of the genus Aspergillus may allow us, in Blake's words, 'to see the world in a grain of sand, and eternity in an hour'. 


\section{Conclusions}

Our study showed the presence of toxigenic Aspergillus species in the rhizosphere of sugarcane. Such occurrence could represent a toxigenic risk for the crop culture in the following year, due to the usual practices of harvesting in Khuzestan province. By testing the in vitro toxin production of fungal species isolated, this study showed their capability of producing OTA, PAT, and FB2, and therefore, this might be the cause of possible contamination of sugarcane plants. These data demonstrate the need for further investigations aimed at assessing the possible risk for human and animal health, due to the consumption of sugarcane products contaminated by mycotoxins.

\section{Materials and Methods}

\subsection{Samples}

Sugarcane fields were sampled from different regions in the South of Iran, depending on the history of cultivation. The sampling was conducted in different stages of sugarcane development, preferably in cold seasons (autumn and winter), with at least 20 well-distributed samples per field, including sugarcane root with the surrounding rhizosphere [38]. Samples were placed in suitable paper envelopes and transferred to the laboratory. After transferring samples to the laboratory, the rhizosphere soil around the root was carefully separated from the root. Samples were divided into soil and root subunits. Soil samples were kept in a ventilated condition and preferably at a temperature of $15-20^{\circ} \mathrm{C}$ for 12 to $24 \mathrm{~h}$ (depending on the moisture content of the soil) and then transferred to the refrigerator $\left(2-5^{\circ} \mathrm{C}\right)$ for further examinations [39].

\subsection{Fungal Isolation and Morphological Identification}

The soil dilution plating technique modified by Johnson et al. [40] and Warcup [41] was used to isolate Aspergillus species from the soil. Soil samples were crushed by a $2 \mathrm{~mm}$ sieve. About 10 gram of the crushed soil was poured into a graduated cylinder. One hundred milliliters of sterile water was added to the cylinder. The suspension was transferred to the $250 \mathrm{~mL}$ Erlenmeyer flask and mixed for 30 minutes. One milliliter of suspension was transferred to test tubes containing $9 \mathrm{~mL}$ of $0.12 \%$ water agar medium. The 1:100, 1:1000, and 1:5000 dilutions were prepared. One milliliter of 1:1000 and 1:5000 dilutions was transferred to Petri dishes and then 10-12 mL of PCA (Potato Carrot Agar) medium [42] containing melted and cooled 1.5\% agar and 1\% oxgall was added. In total, 200 ppm of penicillin and streptomycin antibiotics were also added to avoid bacterial contamination. The plates were moved gently so that the suspension became uniform. For each dilution, three plates were considered. The plates were incubated in the dark at $17{ }^{\circ} \mathrm{C}$ for 10 days. Pure cultures were obtained by single spore isolations. Some representative strains-48 out of the 125 included in the study-were deposited in ITEM (Agri-Food Toxigenic Fungi Culture Collection, ISPA-CNR Bari, Italy, http://server.ispa.cnr.it/ITEM/Collection/) and IRAN (Iranian Fungal Culture Collection, Iranian Research Institute of Plant Protection, Tehran, Iran, http://gcm.wfcc.info/cc/iran).

For morphological characterization, pure cultures were grown on Malt Extract Agar (MEA), and were incubated at $25^{\circ} \mathrm{C}$ for 7 days. Macroscopic traits, such as the colony appearance, color, pigmentation, and growth rate, were recorded according to standard protocols [27,43-45].

\subsection{Molecular Identification}

For molecular identification, isolates were grown on Potato Dextrose Agar (PDA). Direct PCR from fungal mycelia was done using Phire Plant Direct PCR Master Mix (F-160L, Thermo Fisher Scientific, Waltham, USA). For direct PCR, a small piece of growing mycelium from a 3-4-day-old colony was swiped with a sterile pipette tip and re-suspended in $20 \mu \mathrm{L}$ of $1 \times$ Phire Plant Direct PCR Master Mix prior to PCR. Mycelia were crushed with a $100 \mu \mathrm{L}$ pipette tip and vortexed briefly, and then collected down at the tube bottom with a spin in centrifuge. The supernatant $(1 \mu \mathrm{L})$ was used as a template for a $20 \mu \mathrm{L}$ PCR reaction. All amplifications were performed according to standard Direct PCR protocols 
(Tables 1 and 2) by using a GeneAmp 9700 thermalcycler (Applied Biosystems, Foster City, CA, USA). Partial $\beta$-tubulin $(b e n A)$ and partial calmodulin $(C a M)$ genes were amplified using primers described in the literature: primers BT2a and BT2b, and CL1 and CL2A [46,47]. After amplification, amplicons were purified with the enzymatic mixture EXO/SAP (Exonuclease I, E. coli/Shrimp Alkaline Phosphatase) and used as a template for bidirectional DNA sequencing. Sequencing was performed with the BigDye v3.1 terminator kit (Applied Biosystems, Foster City, CA, USA), following the manufacturer's instruction, and analyzed on an ABI 3730 XL Genetic Analyzer (Applied Biosystems, Foster City, CA, USA). Alignment of the two strands was performed using the software package BioNumerics 5.1 (Applied Maths, Sint-Martens-Latem, Belgium)), with manual adjustments, where necessary. Sequences of ben $A$ and CaM genes, generated in this study, were deposited in GenBank with the following accession numbers: from LR693748 to LR693997.

\subsection{Sequence Data Analysis}

To obtain a previous species identification in order to select reference sequences for Aspergillus species to be used in the phylogenetic analysis, sequences of benA and CaM were searched for on the GenBank database using the Basic Local Alignment Tool (BLASTN, NCBI BLAST website). The sequences of 125 strains were used to perform phylogenetic analysis. A set of 16 reference sequences for Aspergillus species, identified by BAST analysis, were downloaded from GenBank and used for phylogenetic analysis. All sequences were aligned using the MUSCLE algorithm [48] with MEGA7 software ver. 7.0.14 [49]. The evolutionary history was inferred by using the Maximum Likelihood method based on the Tamura-Nei model in MEGA7 software [50]. To evaluate the support for inferred topologies, the percentage of trees in which the associated taxa clustered together was calculated by bootstrapping with 1000 replicates [51]. The percentage of trees in which the associated taxa clustered together is shown next to the branches. Initial trees for the heuristic search were obtained automatically by applying Neighbor-Join and Bio NJ algorithms to a matrix of pairwise distances estimated using the Maximum Composite Likelihood (MCL) approach, and then selecting the topology with a superior log likelihood value. The tree was drawn to scale, with branch lengths measured in the number of substitutions per site. The analysis involved 138 nucleotide sequences. Codon positions included were $1 s t+2 n d+3 r d+$ Noncoding. All positions containing gaps and missing data were eliminated.

The phylogenetic approach was based on ben $A$ and CaM concatenated sequences, inferred from 125 strains of Aspergillus examined in this study compared to 13 reference Aspergillus species available at GenBank: A. niger (KACC 45072, AY585542, and JX500080), A. tubingensis (CBS134.48, AY820007, and AJ964876), A. japonicus (ITEM7034, AY585542, and AJ964875), A. welwitschiae (CBS139.54, FJ629291, and KC480196), A. calidoustus (CBS121601, EF591730, and HE616559), A. citrinoterreus (GM228, LN680657, and LN680685), A. floccosus (CBS116.37, FJ491714, and FJ531219), A. hortai (CBS124230, FJ491706, and KP987054), A. luchuensis (KACC46772, JX500062, and JX500071), A. ochraceus (NRRL398, EF661322, and EF661381), A. templicola (DTO267H4, KJ775087, and KJ775371) A. terreus (NRRL255, EF669519, and EF669544), and A. westerdijkiae (NRRL 3174, EF661329, and EF661360).

\subsection{Mycotoxin Analyses}

Methanol, acetonitrile (both for HPLC purposes), and glacial acetic acid were purchased from VWR International Srl (Milan, Italy). Ultrapure water was produced by a Millipore Milli-Q system (Millipore, Bedford, MA, USA). Ochratoxin A (OTA), patulin (PAT), and sterigmatocystin (STG) (purity > 99\%) were produced by Sigma-Aldrich (Milan, Italy). Fumonisin B2 (FB2) was purchased from Biopure (Romer Labs Diagnostic GmbH, Getzersdorf, Austria). An RC $0.2 \mu \mathrm{m}$ filter (regenerated cellulose membranes) was obtained from Grace (Grace Davison Discovery Science, Columbia, DC, USA).

OTA stock solution was prepared by dissolving the solid commercial toxin in methanol (1 mg/mL). The exact concentration of OTA was determined according to the Association of Official Analytical Chemists (AOAC) Official Method 2001.01 [52]. Appropriate aliquots of the stock solution were brought to dryness and reconstituted with acetonitrile/water/acetic acid (99:99:2, v/v/v) to obtain standard 
solutions of OTA in the range $0.05-0.10 \mu \mathrm{g} / \mathrm{mL}$. Fumonisin calibration solutions were prepared by diluting the samples with acetonitrile/water $(1: 1, \mathrm{v} / \mathrm{v})$, to obtain solutions with a concentration in a range of $0.01-1.00 \mu \mathrm{g} / \mathrm{mL}$ for FB1 and FB2. Standard solutions were stored at $-20{ }^{\circ} \mathrm{C}$ and warmed to room temperature prior to use.

PAT stock solution was prepared by dissolving the solid commercial toxin in ethanol $(10 \mu \mathrm{g} / \mathrm{mL})$. The exact concentration of standard solution was determined as reported by the European Committee for Standardization [53]. Aliquots of the stock solution were transferred to $4 \mathrm{~mL}$ amber glass vials and evaporated to dryness under a stream of nitrogen at $50{ }^{\circ} \mathrm{C}$. The residue was dissolved in water/acetonitrile $(85: 15, \mathrm{v} / \mathrm{v})$ to obtain a desired final concentration of 80 to $800 \mathrm{ng} / \mathrm{mL}$.

Mycotoxin stock solution of STG $(1 \mathrm{mg} / \mathrm{mL})$ in acetonitrile was transferred to $4 \mathrm{~mL}$ amber silanized glass vials and evaporated to dryness under a stream of nitrogen at $50{ }^{\circ} \mathrm{C}$. The residue was dissolved in water/methanol $(60: 40, \mathrm{v} / \mathrm{v})$ to obtain calibrant standard solutions from 0.5 to $5.0 \mu \mathrm{g} / \mathrm{mL}$. Standard solutions were stored at $-20{ }^{\circ} \mathrm{C}$ and warmed to room temperature before use. Strains were grown for 14 days on YES (OTA, PAT, and STG), CYA (PAT and STG), and CY20S (FB2) media. One gram of agar was extracted with $5 \mathrm{~mL}$ of extraction solution on an orbital shaker for 60 minutes: OTA and PAT acetonitrile/methanol/water (90: 90: 80, v/v/v), FB2 methanol/water (70:30, v/v), and STG methanol/water (80: 20, v/v). Two milliliters of extracts were evaporated to dryness under a stream of nitrogen at $50{ }^{\circ} \mathrm{C}$.

The quantification of mycotoxins was determined differently. OTA residue was dissolved with $1 \mathrm{~mL}$ of acetonitrile/water/glacial acetic acid (99:99:2, v/v/v) and filtered using RC through a $0.20 \mu \mathrm{m}$ regenerated cellulose filter and determined by HPLC/FLD. OTA quantification was performed according to Susca et al. [35]. The quantification limit (LOQ) was $0.05 \mu \mathrm{g} / \mathrm{g}$ based on a signal to noise ratio of 10:1. FB2 residue was dissolved with $1 \mathrm{~mL}$ of the extract acetonitrile/water (30:70, v/v), filtered using RC $0.20 \mu \mathrm{m}$ filters (Phenomenex, Torrance, CA, USA), and determined by HPLC/FLD previously derivatized with o-phtaldialdehyde (OPA). FB2 quantification was performed according to Susca et al. [35]. The LOQ of the method was $0.1 \mu \mathrm{g} / \mathrm{g}$, based on a signal to noise ratio of 10:1.

PAT residue was dissolved with $1 \mathrm{~mL}$ of water/acetonitrile $(85: 15, \mathrm{v} / \mathrm{v})$ and filtered using $\mathrm{RC}$ through a $0.20 \mu \mathrm{m}$ regenerated cellulose filter and determined by HPLC/DAD. A total of $50 \mu \mathrm{L}$ of extract was injected into HPLC apparatus Agilent 1260 Series. The analytical column was a Luna-C18 $(4.6 \times 150 \mathrm{~mm}, 5 \mu \mathrm{m})$ (Phenomenex, Torrance, CA, USA) preceded by C18 guard column $(4 \times 3 \mathrm{~mm}$, Phenomenex, Torrance, CA, USA). The temperature of the column was maintained at $30{ }^{\circ} \mathrm{C}$. The mobile phase was a mixture of water as solvent $A$ and acetonitrile as solvent $B$, eluted at a flow rate of $1 \mathrm{~mL} / \mathrm{min}$. A gradient elution was performed as follows: 5\% B solvent that was linearly increased by $100 \%$ in $15 \mathrm{~min}$. In these analytical conditions, the retention time of PAT was about 5 min. The diode array detector (DAD) was set at a wavelength of $276 \mathrm{~nm}$. The LOQ was $0.015 \mu \mathrm{g} / \mathrm{g}$, based on a signal to noise ratio of 10:1 [54].

STG residue was dissolved with $1 \mathrm{~mL}$ of water/acetonitrile $(75: 25, \mathrm{v} / \mathrm{v})$ and filtered through RC $0.20 \mu \mathrm{m}$. A total of $50 \mu \mathrm{L}$ of extract was injected into HPLC apparatus Agilent 1260 Series. The analysis of toxins was performed using the following analytical method [55]. The analytical column was a Luna-C18 $(4.6 \times 150 \mathrm{~mm}, 5 \mu \mathrm{m})$ (Phenomenex, Torrance, CA, USA) preceded by C18 guard column $(4 \times 3 \mathrm{~mm}$, Phenomenex, Torrance, CA, USA). The mobile phase consisted of a mixture of acetonitrile/water $(40: 60, \mathrm{v} / \mathrm{v})$ at a flow rate of $0.8 \mathrm{~mL} / \mathrm{min}$. The array detector (DAD) was set at wavelengths of 248 and $328 \mathrm{~nm}$. The temperature of the column was maintained at $30{ }^{\circ} \mathrm{C}$. In this analytical condition, the retention time of ST was about $6.5 \mathrm{~min}$. ST was quantified by measuring peak areas at the retention time of ST standard solutions and comparing these areas with the relevant calibration curve. The LOQ was $0.012 \mu \mathrm{g} / \mathrm{g}$, based on a signal to noise ratio of 10:1.6.

Author Contributions: Conceptualization, M.T.N., A.S., R.Z., and A.F.L.; methodology, M.T.N., M.H., A.S., F.E., and G.S.; validation, M.T.N., M.H., A.S., G.S., and F.E.; formal analysis, M.T.N., M.H., and A.S.; investigation, M.T.N., M.H., and A.S.; resources, M.T.N., V.B., R.Z., B.A., A.S., M.H., and A.F.L.; data curation, M.T.N. and A.S.; writing-original draft preparation, M.T.N., A.M., and A.S.; writing—review and editing, A.S., A.M., M.T.N., R.Z., and B.A.; visualization, M.H., A.S., M.T.N., and E.F.; supervision, A.S., A.F.L., R.Z., B.A., and V.B.; project 
administration, A.S. and A.F.L.; funding acquisition, A.S. and A.F.L. All authors have read and agreed to the published version of the manuscript.

Funding: This research received no external funding.

Acknowledgments: We thank the Sari University, Iranian Research Institute of Plant Protection, and Institute of Sciences of Food Production-CNR for providing facilities for us to conduct this research. The authors also acknowledge Marinella Cavallo of ISPA-CNR for the technical support provided. This work was supported by the Horizon 2020 EU Project 678781 MycoKey.

Conflicts of Interest: The authors declare no conflicts of interest.

\section{References}

1. FAO (Food and Agriculture Organization of the United Nations). FAOSTAT. Available online: http: //faostat.fao.org/faostat/ (accessed on 21 November 2010).

2. Lozano, F.J.; Lozano, R. Assessing the potential sustainability benefits of agricultural residues: Biomass conversion to syngas for energy generation or to chemicals production. J. Clean. Prod. 2018, 172, 4162-4169. [CrossRef]

3. Kumar, D.; Jain, V.K.; Shanker, G.; Srivastava, A. Citric acid production by solid state fermentation using sugarcane bagasse. Process Biochem. 2003, 38, 1731-1738. [CrossRef]

4. Varga, J.; Kevei, F.; Hamari, Z.; Toth, B.; Teren, J.; Croft, H.; Kozakiewicz, Z. Genotypic and phenotypic variability among black aspergilli. In Integration of Modern Taxonomic Methods for Penicillium and Aspergillus Classification; Samson, R.A., Pitt, J.I., Eds.; Harwood Academic Publishers: Amsterdam, The Netherlands, 2000; pp. 397-411.

5. Abarca, M.L.; Accensi, F.; Cano, J.; Cabañes, F.J. Taxonomy and significance of black aspergilli. Antonie Van Leeuwenhoek 2004, 86, 33-49. [CrossRef] [PubMed]

6. Valero, A.; Oliván, A.; Marín, S.; Sancis, V.; Ramos, A.J. Effect of intra and interspecific interaction on OTA production by $A$. section Nigri in grapes during dehydration. Food Microbiol. 2007, 24, 254-259. [CrossRef] [PubMed]

7. Chávez, R.; Bull, P.; Eyzaguirre, J. The xylanolytic enzyme system from the genus Penicillium. J. Biotechnol. 2006, 123, 413-433.

8. Ichishima, E. Development of enzyme technology for Aspergillus oryzae, A. sojae, and A. luchuensis, the national microorganisms of Japan. Biosci. Biotechnol. Biochem. 2016, 80, 1681-1692. [CrossRef] [PubMed]

9. Samson, R.A.; Visagie, C.M.; Houbraken, J.; Hong, S.B.; Hubka, V.; Klaassen, C.H.W.; Perrone, G.; Seifert, K.A.; Susca, A.; Tanney, J.B.; et al. Phylogeny, identification and nomenclature of the genus Aspergillus. Stud. Mycol. 2014, 78, 141-173. [CrossRef] [PubMed]

10. Zambrano, A.Y.; Demey, J.R.; Fuchs, M.; González, V.; Rea, R.; De Sousa, O.; Gutiérrez, Z. Selection of sugarcane plants resistant to SCMV. Plant. Sci. 2003, 165, 221-225. [CrossRef]

11. Abdallah, M.; Krska, R.; Sulyok, M. Mycotoxin contamination in sugarcane grass and juice: First report on detection of multiple mycotoxins and exposure assessment for aflatoxins B1 and G1 in humans. Toxins 2016, 8, 343. [CrossRef]

12. Graham, M.H.; Haynes, R.J. Organic matter status and the size, activity and metabolic diversity of the soil microbial community in the row and inter-row of sugarcane under burning and trash retention. Soil Biol. Biochem. 2006, 38, 21-31. [CrossRef]

13. De Souza, R.S.; Okura, V.K.; Armanhi, J.S.; Jorrín, B.; Lozano, N.; da Silva, M.J.; González-Guerrero, M.; de Araújo, L.M.; Verza, N.C.; Bagheri, H.C.; et al. Unlocking the bacterial, and fungal communities assemblages of sugarcane microbiome. Sci. Rep. 2016, 6, 28774. [CrossRef] [PubMed]

14. Kamei, K.; Watanabe, A. Aspergillus mycotoxins and their effect on the host. Med. Mycol. 2005, 43, 95-99. [CrossRef] [PubMed]

15. Herbrecht, R.; Letscher-Bru, V.; Oprea, C.; Lioure, B.; Waller, J.; Campos, F.; Villard, O.; Liu, K.-L.; Natarajan-Amé, S.; Lutz, P.; et al. Aspergillus galactomannan detection in the diagnosis of invasive aspergillosis in cancer patients. J. Clin. Oncol. 2002, 20, 1898-1906. [CrossRef] [PubMed]

16. Schuster, E.; Dunn-Coleman, N.; Frisvad, J.C.; Van Dijck, P.W. On the safety of Aspergillus niger-A review. Appl. Microbiol. Biotechnol. 2002, 59, 426-435. 
17. Daiani, M.S.; Batista, L.R.; Rezende, E.F.; Fungaro, M.H.P.; Sartori, D.; Alves, E. Identification of fungi of the genus Aspergillus section Nigri using polyphasic taxonomy. Braz. J. Microbiol. 2011, 42, 761-773.

18. Nielsen, K.F.; Mogensen, J.M.; Johansen, M.; Larsen, T.O.; Frisvad, J.C. Review of secondary metabolites and mycotoxins from the Aspergillus niger group. Annal. Bioanal. Chem. 2009, 395, 1225-1242. [CrossRef]

19. Jahromi, M.F.; Liang, J.B.; Ho, Y.W.; Mohamad, R.; Goh, Y.M.; Shokryazdan, P. Lovastatin production by Aspergillus terreus using agro-biomass as substrate in solid state fermentation. J. Biomed. Biotechnol. 2012, 2012, 1-11. [CrossRef]

20. Bizukojc, M.; Pawlak, M.; Boruta, T.; Gonciarz, J. Effect of pH on biosynthesis of lovastatin and other secondary metabolites by Aspergillus terreus ATCC 20542. J. Biotechnol. 2012, 162, 253-261. [CrossRef]

21. Samson, R.A.; Peterson, S.W.; Frisvad, J.C.; Varga, J. New species in Aspergillus section Terrei. Stud. Mycol. 2011, 69, 39-55. [CrossRef]

22. Luque, M.I.; Rodríguez, A.; Andrade, M.J.; Gordillo, R.; Rodríguez, M.; Córdoba, J.J. Development of a PCR protocol to detect patulin producing moulds in food products. Food Control 2011, 22, 831-1838. [CrossRef]

23. Moake, M.M.; Padilla-Zakour, O.I.; Worobo, R.W. Comprehensive review of patulin control methods in foods. Compr. Rev. Food Sci. Food Saf. 2005, 4, 8-21. [CrossRef]

24. Baumgardner, D.J. Soil-related bacterial and fungal infections. J. Am. Board Fam. Med. 2012, 25, 734-744. [CrossRef] [PubMed]

25. Berg, G.; Eberl, L.; Hartmann, A. The rhizosphere as a reservoir for opportunistic human pathogenic bacteria. Environ. Microbiol. 2005, 7, 1673-1685. [CrossRef]

26. Leger, R.J.S.; Screen, S.E.; Shams-Pirzadeh, B. Lack of host specialization in Aspergillus flavus. Appl. Environ. Microbiol. 2000, 66, 320-324. [CrossRef]

27. Klich, M.A. Identification of Common Aspergillus Species; Centraalbureau voor Schimmelcultures: Utrecht, The Netherlands, 2002.

28. Hariprasad, P.; Vipin, A.V.; Karuna, S.; Raksha, R.K.; Venkateswaran, G. Natural aflatoxin uptake by sugarcane (Saccharum officinaurum L.) and its persistence in jaggery. Environ. Sci. Pollut. Res. 2015, 22, 6246-6253. [CrossRef] [PubMed]

29. Palumbo, J.D.; Baker, J.L.; Mahoney, N.E. Isolation of bacterial antagonists of Aspergillus flavus from almonds. Microb. Ecol. 2006, 52, 45-52. [CrossRef] [PubMed]

30. Djossou, O.; Perraud-Gaime, I.; Mirleau, F.L.; Rodriguez-Serrano, G.; Karou, G.; Niamke, S.; Ouzari, I.; Boudabous, A.; Roussos, S. Robusta coffee beans post-harvest microflora: Lactobacillus plantarum sp. as potential antagonist of Aspergillus carbonarius. Anaerobe 2011, 17, 267-272. [CrossRef] [PubMed]

31. Gajera, H.P.; Vakharia, D.N. Molecular and biochemical characterization of Trichoderma isolates inhibiting a phytopathogenic fungi Aspergillus niger Van Tieghem. Physiol. Mol. Plant. Pathol. 2010, 74, 274-282. [CrossRef]

32. Hill, R.A.; Blankenship, P.D.; Cole, R.J.; Sanders, T.H. Effects of soil moisture and temperature on preharvest invasion of peanuts by the Aspergillus flavus group and subsequent aflatoxin development. Appl. Environ. Microbiol. 1983, 45, 628-633. [CrossRef]

33. Susca, A.; Proctor, R.H.; Morelli, M.; Haidukowski, M.; Gallo, A.; Logrieco, A.F.; Moretti, A. Variation in fumonisin and ochratoxin production associated with differences in biosynthetic gene content in Aspergillus niger and A. welwitschiae isolates from multiple crop and geographic origins. Front. Microbiol. 2016, 7, 1412. [CrossRef]

34. Medina, A.; Mateo, R.; López-Ocana, L.; Valle-Algarra, F.M.; Jiménez, M. Study of Spanish grape mycobiota and ochratoxin A production by isolates of Aspergillus tubingensis and other members of Aspergillus section Nigri. Appl. Environ. Microbiol. 2005, 71, 4696-4702. [CrossRef] [PubMed]

35. Susca, A.; Proctor, R.H.; Butchko, R.A.; Haidukowski, M.; Stea, G.; Logrieco, A.F.; Moretti, A. Variation in the fumonisin biosynthetic gene cluster in fumonisin-producing and nonproducing black aspergilli. Fungal Genet. Biol. 2014, 73, 39-52. [CrossRef] [PubMed]

36. Marino, A.; Fiorentino, C.; Spataro, F.; Nostro, A. Effect of temperature on production of ochratoxin A by Aspergillus niger in orange juice. J. Toxins 2014, 2014, 1-5. [CrossRef]

37. Abarca, M.L.; Bragulat, M.R.; Castella, G.; Cabañes, F.J. Ochratoxin A production by strains of Aspergillus niger var. niger. Appl. Environ. Microbiol. 1994, 60, 2650-2652. [CrossRef] [PubMed]

38. Singleton, L.L.; Mihailm, J.D.; Rush, C.M. Methods for research on soilborne phytopathogenic fungi. In The American Phytopathological Society; APS Press: St Paul, MI, USA, 1993; Volume 85, pp. 140-141. 
39. Bills, G.F.; Christensen, M.; Powell, M.; Thorn, G. Saprobic soil fungi. In Biodiversity of Fungi: Inventory and Monitoring Methods; Muller, G.M., Bills, G.F., Foster, M.S., Eds.; Elsevier Academic Press: Burlington, MA, USA, 2004; pp. 271-302.

40. Johnson, L.F.; Curl, E.A.; Bond, J.H.; Fribourg, H.A. Methods for Studying Soil Mycoflora: Plant Disease Relationships; Burgess Publishing: Minneapolis, CO, USA, 1960; p. 179.

41. Warcup, I.M. Method for Isolation and Estimation of Activity of Fungi in Soil. In The Ecology of Soil. An International Symposium; Liverpool University Press: Liverpool, UK, 1960; pp. 3-21.

42. Gams, W.; Howekstra, E.S.; Aptroot, A. CBS Course of Mycology; Centraalbureau voor Schimmelcultures: Utrecht, The Netherlands, 1998; pp. 1-165.

43. Raper, K.B.; Fennell, D.I. The Genus Aspergillus; Williams \& Wilkins: Baltimore, MD, USA, 1965; p. 114.

44. Pitt, J.; Hocking, A. The ecology of Fungal Food Spoilage. In Fungi and Food Spoilage; Blackie Academic and Professional: London, UK, 2009; pp. 3-9.

45. Samson, R.A.; Houbraken, J.; Thrane, U.; Frisvad, J.C.; Andersen, B. Food and Indoor Fungi; CBS KNAW Biodiversity Center: Utrecht, The Netherlands, 2010.

46. Glass, N.L.; Donaldson, G.C. Development of primer sets designed for use with the PCR to amplify conserved genes from filamentous ascomycetes. Appl. Environ. Microbiol. 1995, 61, 1323-1330. [CrossRef] [PubMed]

47. O'Donnell, K.; Nirenberg, H.I.; Aoki, T.; Cigelnik, E. A Multigene phylogeny of the Gibberellafujikuroi species complex: Detection of additional phylogenetically distinct species. Mycoscience 2000, 41, 61-78. [CrossRef]

48. Edgar, R.C. MUSCLE: Multiple sequence alignment with high accuracy and high throughput. Nucleic Acids Res. 2004, 32, 1792-1797. [CrossRef]

49. Kumar, S.; Stecher, G.; Tamura, K. MEGA7: Molecular evolutionary genetics analysis version 7.0 for bigger datasets. Mol. Biol. Evol. 2016, 33, 1870-1874. [CrossRef]

50. Tamura, K.; Nei, M. Estimation of the number of nucleotide substitutions in the control region of mitochondrial DNA in humans and chimpanzees. Mol. Biol. Evol. 1993, 10, 512-526.

51. Felsenstein, J. Confidence limits on phylogenies: An approach using the bootstrap. Evolution 1985, 39, 783-791. [CrossRef]

52. Association of Official Analytical Chemists (AOAC) Official Method 2008-08. Available online: http: //www.aoacofficialmethod.org/index.php?main_page=product_info\&cPath=1\&products_id=2816 (accessed on 16 August 2016).

53. CEN (European Committee for Standardization). Foodstuffs-Determination of patulin in fruit juice and fruit based puree for young children-HPLC method with liquid/liquid partition clean-up and solid phase extraction and UV determination. CEN/TC 275/WG5. In Food analysis-Biotoxins-Foodstuffs-EN 15890; CEN: Brussels, Belgium, 2002.

54. Sewram, V.; Nair, J.J.; Nieuwoudt, T.W.; Leggott, N.L.; Shephard, G.S. Determination of patulin in apple juice by high-performance liquid chromatography-atmospheric pressure chemical ionization mass spectrometry. J. Chromat A 2000, 897, 365-374. [CrossRef]

55. Veršilovskis, A.; De Saeger, S.; Mikelsone, V. Determination of sterigmatocystin in beer by high performance liquid chromatography with ultraviolet detection. W. Mycotox. J. 2008, 1, 161-166. [CrossRef]

(C) 2020 by the authors. Licensee MDPI, Basel, Switzerland. This article is an open access article distributed under the terms and conditions of the Creative Commons Attribution (CC BY) license (http://creativecommons.org/licenses/by/4.0/). 